\title{
PATTERNS OF ADOPTION OF AGILE TOOLS
}

\author{
Roger Maull ${ }^{1}$, Wendy Maull ${ }^{2}$ and Alan Brown ${ }^{1}$ \\ ${ }^{1}$ University of Exeter Business School, UK \\ ${ }^{2}$ Maull Solutions Ltd, UK
}

\begin{abstract}
This short paper conducts a factor analysis of the adoption of Agile tools using data from the $14^{\text {th }}$ state of agile survey. Our results suggest that organizations adopt combinations of tools that do not align to any Agile methodology and may reflect organizational role and historical development. Future research should focus on tool adoption not methodology.
\end{abstract}

\section{KEYWORDS}

Agile Methodology, Agile Techniques, Scrum, XP, Kanban

\section{INTRODUCTION}

Agile is now the preferred methodology for accelerated and risk-reduced software development with organizations of all sizes committed to Agile approaches to help themselves to compete, improve and transform. The key characteristics of agile methods were summarized and promoted through an "agile manifesto" (Fowler and Highsmith, 2001) created by a group of prominent software delivery experts They highlighted a set of values considered fundamental to these agile ways of working that encouraged a focus on: individuals and interactions over processes and tools; working software over comprehensive documentation; customer collaboration over contract negotiations and responding to change over following a plan.

This set of priorities led to an emphasis change in software delivery; a move away from heavyweight process-based methods towards more flexible experiment-based methods such as Scrum (Schwaber and Beedle 2002), Extreme Programming (XP) (Beck and Fowler 2001), Kanban (Anderson 2010) amongst many others.

The most comprehensive study into the adoption of agile approaches, now in its $14^{\text {th }}$ year, is the State of Agile Report (digital.ai 2020). Accessing and downloading the full set of reports reveals some interesting observations. Over these 14 years the biggest change has been the increasing importance of agile to aligning the business and IT with a consistent increase in the number of teams adopting agile to the point where in the latest survey approximately $33 \%$ of respondents respond that half of their teams have adopted agile and around $20 \%$ saying all their teams have. The reasons why agile was chosen has remained consistent across the 14 years with the top reason being to accelerate time to market/software delivery followed by enhancing the ability to manage changing priorities, improving alignment between IT and the business and increasing team productivity.

However, the data on how organizations are approaching agile adoption offers a far more mixed picture. Over the 14 years Scrum has gradually increase from $40 \%$ of respondents to $58 \%$, Kanban from a 0 to $7 \%$ in the same period, whilst noticeably Extreme Programming (XP) has moved from $23 \%$ to a barely negligible $1 \%$ in year 14. Over the 14 years there has also been an emergence of hybrid approaches such as ScrumBan from 0 to $10 \%$ at the same time as a rapid reduction in Scrum/XP from 23\% 8\%. At the level of the 'methodology' the picture appears clear: scrum is the dominant approach. However, this contrasts with questions posed around agile techniques and practices where for example the use of Kanban boards has moved from zero to $76 \%$ by year 14, with large numbers continuing to use XP methods such as Mapping tools (54\%) re-factoring (26\%) et cetera. Clearly, there is some significant blurring of the methodological distinctions and organizations are adopting a 'what works for us' approach.

In this short paper, we aim to use data from the state of agile report data to further investigate approaches to agile development through considering the differences between methodology and tools and techniques to begin to develop taxonomy of approaches to agile adoption. It is unclear from research what these combinations are and therefore our research question is: what are the combinations of tools that organizations are adopting? 


\section{LITERATURE}

Agile methodologies contrast with the more traditional 'waterfall' approaches by accentuating aspects such as flexibility in scope and an ongoing continuous approach to design with an emphasis on engaging with the customer, allowing and even encouraging ambiguity and freezing the system design as late as possible (Serrador and Pinto 2015). In their article 'embracing agile' Rigby, Sutherland and Takeuchi (2016) claim that agile methods are a radical alternative to the traditional hierarchical project management techniques and have developed new sets of practices and principles that have revolutionized the technology industry and 'greatly increased' software development success rates over the last 25-30 years. Gandomani et al. (2013) identified four categories of challenges faced by organizations when migrating to agile: organization and management; people; process; and tools related challenges. Our focus in this short paper is on the tools related challenges.

Many of the published studies on approaches to agile focus on the overall methodology typically by comparing XP, Scrum and Kanban. Matharu et al (2015) has usefully described the distinguishing features of each. He typifies Scrum as having a focus on: cross functional teams; daily meetings; products and sprint backlogs and the identification of three primary roles, the product owner, development team and scrum master. The distinguishing features of XP are: the formulation of requirements using story cards; the simplest possible design: a continuous interaction with the customer: test driven development: re-factoring existing solutions and pair programming. Finally, Kanban is a method which emphasizes the delivery of software just in time for implementation. Its distinguishing characteristics are: the use of kanban boards; maximizing productivity by reducing idle time: the continuous delivery of software increments: the minimization of waste and the limitation of work in progress.

Hummel (2014) has summarized the literature on agile systems development from 482 papers reporting that despite the widespread popularity of Scrum in industry, most research was based on based on XP and particularly the practices of pair programming, unit testing and refactoring practices of which most studies of the last two were mainly conceptual.

In practice, differentiating between methodologies is difficult with organizations adopting a 'what works' and 'mix and match' approach. The literature is full of examples. For example, Azizyan et al (2011) note that summing the percentages of the Agile methods used in their survey results in $114 \%$. implying that some organizations followed more than one Agile method. In specific case examples, Petersen and Wohlin (2009) reported that Ericsson used a hybrid agile methodology consisting of Scrum and XP as well as other general development practices and Murphy et al (2013) found no clear trends in practice adoption at Microsoft, concluding that tool availability may be a greater driver of practice adoption than methodology. Finally, Sjoberg, Johnson and Solberg (2012) report their case company stating that being rigorous with agility just because it is written in theoretical books showing toy examples is of no business value.

This paper focuses on the approach to agile, specifically tool use and the combination of tools that are used. It is our contention that grouping of tools may not be in alignment with any particular methodology but much more of a mix and match approach that adapts to the company need.

\section{METHOD}

To consider our research question we partnered with digital.ai. For the past 14 years, digital.ai has conducted an annual survey, The State of Agile which is widely quoted across the industry. The 2019 questionnaire asked 29 questions across seven broad areas: why agile; time and ability with agile; distributed teams and outsourcing; scaling agile; agile tools used, DevOps and the value and success of agile. We were provided with the raw data from the section on agile tools from the $14^{\text {th }}$ survey to conduct our analysis.

The survey had 1121 completed questionnaires with the following characteristics. $41 \%$ of respondents were from companies between 1-1000 employees, 19\% between 1000 and 5000, $15 \%$ between 5000 and 20,000 25\% over 20,000. $41 \%$ of the respondents were from North America, 31\% from Europe, 13\% from Asia and 15\% from the rest of the world. In terms of their role, $37 \%$ were scrum masters or internal coaches, $14 \%$ project or programme managers, $13 \%$ development leadership, $7 \%$ development team member and $7 \%$ external consultants, $6 \%$ product managers and $18 \%$ other. Their main industry types were technology at $26 \%$, financial services at $17 \%$ and professional services at $7 \%$. 


\section{RESULTS}

The general results from the survey (digital.ai 2020) show that the overwhelming methodology being used was Scrum at $59 \%$ of respondents and $77 \%$ in hybrid form with XP and Kanban. Most notably XP was now down at $1 \%$ suggesting that it is now more frequently being blended with other approaches.

Our analysis is at the level of agile tool. Here we saw much greater diversity. We downloaded the raw data from the 2019 survey into SPSS and we used factor analysis on the 22 variables containing responses to Q23 of the questionnaire: Which agile planning \& delivery tools do you currently use or plan to use in the next 12 months? The responses were coded as 1: currently use, 2: plan to use, 3: do not use or plan to use, so a higher score represented a lower use of the technique. This was considered in interpreting the results.

1202 cases had enough responses to be included in the analysis ( 81 more than the fully completed questionnaires). The KMO measure of sampling Adequacy was .913 and Bartlett's Test of Sphericity yielded Approx Chi-square of 6427, df 231, sig .000. Five components had eigenvalues $>1$, explaining $51 \%$ of variance in these variables. These were then rotated using Varimax rotation to yield the table below. Coefficients below 0.4 have been suppressed for clarity.

Table 1. Factor Analysis

\begin{tabular}{|c|c|c|c|c|c|}
\hline & \multicolumn{5}{|c|}{ Component } \\
\hline & 1 & 2 & 3 & 4 & 5 \\
\hline Automated Build Tool & 0.828 & & & & \\
\hline $\begin{array}{l}\text { Continuous Integration } \\
\text { Tool }\end{array}$ & 0.777 & & & & \\
\hline Unit Test Tool & 0.714 & & & & \\
\hline $\begin{array}{l}\text { Release/Deployment } \\
\text { Automation Tool }\end{array}$ & 0.703 & & & & \\
\hline Bug Tracker & 0.648 & & & & \\
\hline Wiki & 0.553 & & & & \\
\hline $\begin{array}{l}\text { Automated Acceptance } \\
\text { Test Tool }\end{array}$ & 0.502 & & & & \\
\hline \multicolumn{6}{|l|}{$\begin{array}{l}\text { Requirements } \\
\text { Management Tool }\end{array}$} \\
\hline Story Mapping Tool & & 0.689 & & & \\
\hline Timecards & & 0.589 & & & \\
\hline $\begin{array}{l}\text { Customer ldea } \\
\text { Management Tool }\end{array}$ & & 0.574 & & & \\
\hline Refactoring Tool & 0.455 & 0.532 & & & \\
\hline Spreadsheet & & & 0.73 & & \\
\hline $\begin{array}{l}\text { Traditional Project } \\
\text { Management Tool }\end{array}$ & & & 0.683 & & \\
\hline Static Analysis & & & 0.462 & & \\
\hline \multicolumn{6}{|l|}{ Taskboard } \\
\hline $\begin{array}{l}\text { Project \& Portfolio } \\
\text { Management (PPM) Tool }\end{array}$ & & & & 0.623 & \\
\hline $\begin{array}{l}\text { Agile Project } \\
\text { Management Tool }\end{array}$ & & & & 0.617 & \\
\hline Kanban Board & & & & 0.57 & 0.474 \\
\hline Index Cards & & & & & 0.616 \\
\hline Product Roadmapping & & & & & 0.573 \\
\hline Wireframes & 0.41 & & & & 0.458 \\
\hline
\end{tabular}




\section{ANALYSIS}

Our analysis of the factors categorized the findings as follows.

\section{Factor 1 Dev Ops}

Fundamental to agile delivery scenarios, this set of tools are typical of those teams responsible for delivering a stream of quality features into production. The focus on Devops emphasizes a strong testing capability aligned with Continuous Integration and Continuous Delivery (CD/CI) practices.

\section{Factor 2 Agile Planning}

The use of combination of early-stage analysis tools is typical of those involved in agile planning activities. Here, close attention is paid to describing customer needs and to converting them into meaningful stories as the basis for further elaboration.

\section{Factor 3 Traditional Quality Assurance and Project Management}

Every large-scale organization has a heritage of common management tools and occupies substantial time creating spreadsheets for tracking progress. Much as agile purists rail against it, traditional project management persists and is ubiquitous. Their use is a daily reality for numerous individuals with management and quality assurance responsibilities.

\section{Factor 4 Agile Project Management}

As agile techniques become more widely adopted in an organization, the use of agile project management tools becomes common. These are essential to increase visibility and support agile rituals such as standup meetings, sprint reviews, and retrospectives.

\section{Factor 5 Product Management and Design}

The design, management, and delivery of products is central to agile approaches. The product manager holds a key role aligning customer needs, business priorities, and engineering capabilities. Support for product managers includes defining key product features and increasing the visibility of work in progress.

In their study Azizyan et al (2011) found that there were 32 different agile project management tools mentioned in their survey results which they grouped under five different types: agile project management tools for example scrum works; basic tools such as sticky notes: spreadsheets: traditional project management tools for example Microsoft project and finally custom built tools. This grouping seems somewhat simplistic and our groupings of 22 tools/techniques indicate a more complex set of combinations which do not appear to align to any methodological pure approach. This has important implications for those researching agile adoption, clearly pointing out that organizations are mixing tools and not adopting any pure methodological approach despite a large number identifying with a particular methodology (59\% stated Scrum in this survey).

\section{CONCLUSIONS}

This research has provided strong evidence that organizations are adopting a mix and match approach to agile adoption and not following a 'pure' methodological approach. Our five factors show some intriguing combinations. For example, there is clear evidence of traditional approaches to project management continuing to exist under an agile banner. Furthermore, there is some indication that the remaining four are influenced by the different roles that respondents hold in an organization. This suggests that instead of a focus on the organization and its methodology, the focus may need to be on the individual role and the way in which participants view implications of agile techniques for each function. A second implication is that we may also be seeing the importance of the impact of organizational heritage and the influence that has on practices that are adopted in the organization. Although agile evangelists might argue for a focus on product not project, projects are the heritage and maintain a strong influence on techniques that are adopted.

There are some significant limitations in this research. Despite a relatively large sample we have no way of knowing if this is representative of the population of agile users and we have not tested our results against another population. We recognize that our factor analysis explains $51 \%$ variance and although each of the factors explains more than a single variable, they will require further analysis than are indicated in these preliminary results. Future work will be to investigate the data further. We have plans to look to cluster cases by using our five factors and the demographic data to identify clusters of cases, and therefore develop a more rigorous taxonomy of agile approaches. 


\section{REFERENCES}

Anderson, D.J., 2010. Kanban: successful evolutionary change for your technology business. Blue Hole Press.

Azizyan, G., Magarian, M.K. and Kajko-Matsson, M., 2011, August. Survey of agile tool usage and needs. In 2011 agile conference (pp. 29-38). IEEE.

Beck, K. and Fowler, M., 2001. Planning extreme programming (Vol. 200). Reading: Addison-Wesley.

Fowler, M. and Highsmith, J., 2001. The agile manifesto. Software Development, 9(8), pp.28-35.

Gandomani, T.J., Zulzalil, H., Ghani, A.A.A., Sultan, A.B.M. and Nafchi, M.Z., 2013. Obstacles in moving to agile software development methods; at a glance. Journal of Computer Science, 9(5), p.620.

Hummel, M., 2014, January. State-of-the-art: A systematic literature review on agile information systems development. In 2014 47th Hawaii International Conference on System Sciences (pp. 4712-4721). IEEE.

Matharu, G.S., Mishra, A., Singh, H. and Upadhyay, P., 2015. Empirical study of agile software development methodologies: A comparative analysis. ACM SIGSOFT Software Engineering Notes, 40(1), pp.1-6.

Murphy, B., Bird, C., Zimmermann, T., Williams, L., Nagappan, N. and Begel, A., 2013, October. Have agile techniques been the silver bullet for software development at microsoft?. In 2013 ACM/IEEE international symposium on empirical software engineering and measurement (pp. 75-84). IEEE.

Petersen, K and C. Wohlin, "A comparison of issues and advantages in agile and incremental development between state of the art and an industrial case," Journal of Systems and Software, vol. 82, no. 9, pp. 1479-1490, Sept. 2009

Rigby, D.K., Sutherland, J. and Takeuchi, H., 2016. Embracing agile. Harvard Business Review, 94(5), pp.40-50.

Schwaber, K. and Beedle, M., 2002. Agile software development with Scrum (Vol. 1). Upper Saddle River: Prentice Hall.

Serrador, P. and Pinto, J.K., 2015. Does Agile work?-A quantitative analysis of agile project success. International Journal of Project Management, 33(5), pp.1040-1051.

Sjøberg, D.I., Johnsen, A. and Solberg, J., 2012. Quantifying the effect of using kanban versus scrum: A case study. IEEE software, 29(5), pp.47-53.

Stateofagile.com, accessed $31^{\text {st }}$ December 2020. 